\title{
Myanmar's Current Transportation System Concerning with Development
}

\author{
Ei Thinzar Min \\ Deputy Staff Officer, Department of International Relations, \\ House of Representatives,
}

\begin{abstract}
Transportation plays as an important role for developing countries actually. Currently, Myanmar is also in transition period to the democratic governance that containing reforms to upgrade the quality of transportation system because living standards of a nation are directly related to the development of the transportation. The development of transport activities of a nation is the ability to deliver transport systems which will prosper the economic, social and political segments of the nation. There is no doubt that good transportation can make to become national development absolutely. If Myanmar can effectively change the challenges and difficulties such as transportation and policy to opportunities, it will certainly become a developed country within short period.
\end{abstract}

Keywords: Transportation, National Development, Highway Road, Geographical Conditions, Challenges, Opportunities.

\section{INTRODUCTION}

Development is crucial role to the sustenance and growth of any nation. Transportation is a non-separable part with any societies. The richest and most powerful nations in the world have an efficient transport system absolutely. The growing share of the wealth of any nation is linked to its trade and distribution. Developing countries use to carefully maintain about their transportations systems to be sustainable for national development. The living standards around the world radically increased and developed since a few years ago. On the other hand, good transportation process makes easier, safer, faster, more reliable and convenient to carry and transport the goods. And then, goods could be shipped around the world and traded for other products due to easier route of transportations. Improving the transportation system is a key to encouraging development.

\section{A. Research Questions}

1. What are the transportation systems in Myanmar?

2. What are the plans being implemented aiming at the development of transportation in Myanmar?

3. How does transportation impact for the development of Myanmar?

\section{B. Research Methods}

The research method used in this study is a literature analysis.

\author{
Nay Pyi Taw, Myanmar \\ Master student, School of Business, Guangxi University, \\ Nanning, China
}

\section{LITERATURE REVIEW}

\section{A. Background Information Of Myanmar}

The current population of Myanmar is 54,335,948 as of Saturday, April 18, 2020, based on Worldometer. The total land area is $653,290 \mathrm{Km}^{2}(252,237$ sq. miles $)$. $31.4 \%$ of the population is urban $(17,068,066$ people in 2020) Myanmar is divided into seven states, seven regions, and the Union Territory of the capital, Nay Pyi Taw. Yangon is the Commercial city and the Cultural city is Mandalay. There are many neighboring countries such as China, Laos, Bangladesh, Thailand and India. Myanmar is now performing at a historic milestone in its transition into a market economy and democracy. Since 2011, the country has been transformed to a fundamental political, economic, and social transformation at unprecedented speed and scope, after decades of isolation and stagnation.

\section{B. Current Basic Transportation System In Myanmar}

In Myanmar, the Ministry of Transport and Communications (MOTC) supervises the various departments, directorates and state-owned enterprises which were founded in 1992. Integrated Transport Information System introduced in passenger transportation. Prior to the implementation of the new bus network, The Yangon Bus Service system (YBS) was launched on 16 January, 2017, during the incumbent government's term. At present, there are more than 100 bus lines which are operating 4,500 buses on about 135 routes, along with the Airport Shuttle. The number of daily commuters has been estimated at 1.8 million. And also E-ticketing machines have been installed on more than 2,500 buses with the YBS lines for the rollout of the card payment system. Yangon's bus network was overseen by the Yangon Motor Vehicles Supervisory Committee and gave a service for the majority of the city's 2.8 million commuters daily. And then, there are two highway bus gates in Myanmar such as Mandalay High Way Bus Gate and Yangon Highway Bus Gate. In Myanmar, this two main gates are currently so important to go everywhere around the country.

\section{Transportation Development In Myanmar}

Myanmar is one of the developing countries and the vehicle ownership was low in Myanmar before. Although the rate of Traffic volume increased, there are not enough road infrastructures for that. Investment has emphasized on major highways and new railways, with little funding for the operation and maintenance of the existing networks, especially for the lower-level road networks. The higher- 
level roads are underutilized while access to regional towns and communities is very poor. Transport costs are high and access to economic and social opportunities for much of the population is severely limited It is necessary to improve domestic connectivity through more efficient transport linkages between rural areas, markets, and urban centers. It is also important to connect with neighboring countries.

Nearly half of Myanmar's rural population does not have access to all-weather roads, a challenge exacerbated by weak inland waterways and underdeveloped river ports, which in turn drives up transport costs, limits access to markets and services, and contributes to rural poverty. The 20 million people in the country still lack basic road access, $60 \%$ of highways are in poor condition. Proposals to increase investment in transport could also help facilitate cross-border trade ties with regional countries. Road connectivity remains limited in Myanmar.

Meanwhile, ongoing upgrades to the YME (YangonMandalay Expressway) will likely see the entire road repaved with asphalt before FY 2020/2021(Fiscal Year). To increase safety and reduce traffic accidents, a particular 64$\mathrm{km}$ stretch of the road near Yangon will be expanded to four lanes and outfitted with modern safety equipment, with the help of the ADB (Asia Development Bank).

\section{FINDINGS}

Ministry of Construction, Myanmar established and opened Yangon-Nay Pyi Taw-Mandalay Highway Road in December 2010. By this highway road, Myanmar people can go quickly from Yangon (Lower Region of Myanmar) to Mandalay (Upper Region of Myanmar) that goods can distribute from lower region to upper region in Myanmar. This Yangon- Mandalay Express was has reduced the travel times between Yangon and Mandalay than before. On the other hand, Road connectivity remains limited in Myanmar. Transportation also depends on the geographical conditions of a country. In Myanmar, most of roads in coastal, western, southern and mountainous areas are in very poor conditions, usually offering just one lane to traffic with large stretches of unpaved dirt and gravel that are unusable during monsoon season.

Myanmar government has indicated to improve infrastructure projects including land connectivity, transportation links with regional economies to boost economic integration and improvement of basics amenities to transform Myanmar into a world class green metropolis. Since 2012, the government of Myanmar has been planning the National Transport Master Plan. The implementation of the projects under the Master Plan is approved by the Cabinet and there are 142 proposed projects for road, rail, and maritime, inland water, transport, and air sectors.

Myanmar's transport sector is overseen by the Ministry of Transport and Communications (MOTC). Focal departments governing the sector under the MOTC include (1) Department of Civil Aviation (DCA), (2) Directorate of Water Resources and Improvement of River Systems (3)
Department of Marine Administration (DMA) and (4) Road Transport Administration Department (RTA) respectively. Other transit authorities include Myanmar National Airlines (MNA), which is the national flag carrier; the Myanmar Port Authority, which comes under the jurisdiction of the DMA and is responsible for running key national ports; and Myanmar Railways (MR), which is the national rail operator. Meanwhile, the Ministry of Agriculture, Livestock and Irrigation is in charge of rural roads and bridges, while roads in the border regions are the responsibility of the Ministry of Border Affairs. The Yangon Region Transport Authority (YRTA) is in charge of the transport network in and around the city. Other important stakeholders in Yangon include the Yangon Regional Government and the Yangon City Development Committee.

In Myanmar, there have been 151,298km; among them $39,076 \mathrm{~km}$ is paved road. The country's internal road network is presently insufficient to service a country of $676,578 \mathrm{sqkm}$. Vehicle registration has more than tripled in a decade but daily travel in Yangon has slow down by two to three times. New types of public transport are being introduced with the new Yangon Bus Service launched in February 2016. There are five main overland crossings with Thailand and one of each other with China and India. Road transport dominates not only long-distance travel, with $90 \%$ of freight transport but also $86 \%$ of passenger transport. The longest network of rail lines have with 412 locomotives among the ASEAN countries, in Myanmar, 960 stations, 1375 passenger coaches and 3384 wagons. Myanmar possessed a long coastline with growth in volumes of imports and exports providing connections with other ports. Yangon Port momentarily handles $85 \%$ of Myanmar's import and export. Myanmar's ports have an essential to become regional transportation hubs serving markets in China, India and Indo-China region because of the possibility to save shipping time via over-land transport through Myanmar. Excluding Yangon, Myanmar has nine costal ports. For the Agriculture sector, River Freight transportation is consisted of commodity items.

\section{DISCUSSION}

Myanmar's transport sector has remained from the lack of international expertise, experience, investment and loss of capacity in the agencies currently. This applies widely to all of the transport subsectors that are roads, railways, ports, inland waterways, and civil aviation. Identifying priorities will be critical for the government as it moves to improve cross-border trade, meet rising air passenger demand, capitalize on regional growth trends and reduce transport time and costs. The creation of a codified PPP (Public-Private Partnership) framework will be paving the way for future transport project investment. It is important to take awareness of the negative impact arising from the transport system; therefore, flexible measures must be taken for sustainable development. 


\section{CONCLUSION}

Although Myanmar is moving towards the developed country, it should be considered that transportation is one of the primary goals of national development. Our government is currently fulfilling with necessities and many difficulties at any sectors that lead to become impacts and challenges to develop the economic sector in Myanmar. In addition, it is needed to allocate the financial supporting in order to improve the transportation sector in our country. Therefore, transportation is essential for the development of a country actually.

\section{REFERENCES}

[1]. Myanmar National Transport Master plan-2014 presentation

[2]. Transport sector in Myanmar (Hnin Hnin Aye)

[3]. Transportation and National Development

[4]. Activities for sustainable development of transport sector In Myanmar

[5]. Survey program for national transport development plan

[6]. Intelligent transport system of transport sector in Myanmar

[7]. Myanmar transport brief

[8]. Myanmar-General- Transport-2017

[9]. The global new light of Myanmar

[10]. Ministry of Transportation and Communication in Myanmar

[11]. Myanmar-reform-transport-instution 